\title{
Sensitivity Enhancement of Benzene Sensor Using Ethyl Cellulose- Coated Surface-Functionalized Carbon Nanotubes
}

\author{
Thanattha Chobsilp, ${ }^{1}$ Worawut Muangrat, ${ }^{2}$ Chaisak Issro, ${ }^{1}$ Weerawut Chaiwat, ${ }^{3}$ \\ Apiluck Eiad-ua, ${ }^{4,5}$ Komkrit Suttiponparnit, ${ }^{6}$ Winadda Wongwiriyapan ${ }^{1},{ }^{4,5}$ \\ and Tawatchai Charinpanitkul ${ }^{7}$
}

\author{
${ }^{1}$ Department of Physics, Faculty of Science, Burapha University, Long-Hard Bangsaen Rd., Muang, Chonburi 20131, Thailand \\ ${ }^{2}$ Institute of Carbon Science and Technology, Shinshu University, 4-17-1 Wakasato, Nagano 380-8553, Japan \\ ${ }^{3}$ Environmental Engineering and Disaster Management Program, Mahidol University, Kanchanaburi Campus, Sai yok, \\ Kanchanaburi 71150, Thailand \\ ${ }^{4}$ College of Nanotechnology, King Mongkut's Institute of Technology Ladkrabang, Chalongkrung Rd., Ladkrabang, \\ Bangkok 10520, Thailand \\ ${ }^{5}$ Nanotec-KMITL Center of Excellence on Nanoelectronic Devices, Chalongkrung Rd., Ladkrabang, Bangkok 10520, Thailand \\ ${ }^{6}$ Environmental Technology Research Department, Innovation Institute, PTT Public Company Limited, Wangnoi, \\ Ayutthaya 13170, Thailand \\ ${ }^{7}$ Center of Excellence in Particle Technology, Faculty of Engineering, Chulalongkorn University, Pathumwan, \\ Bangkok 10330, Thailand
}

Correspondence should be addressed to Winadda Wongwiriyapan; winadda.wo@kmitl.ac.th

Received 31 August 2017; Revised 28 November 2017; Accepted 5 December 2017; Published 20 May 2018

Academic Editor: Banshi D. Gupta

Copyright (c) 2018 Thanattha Chobsilp et al. This is an open access article distributed under the Creative Commons Attribution License, which permits unrestricted use, distribution, and reproduction in any medium, provided the original work is properly cited.

\begin{abstract}
A hybrid sensor based on the integration of functionalized multiwalled carbon nanotubes (MWCNTs) with ethyl cellulose (EC) was fabricated for sensitivity enhancement of benzene detection. To functionalize the surface of MWCNTs, MWCNTs were treated with hydrochloric acid for $60 \mathrm{~min}$ (A60-MWCNTs), while other MWCNTs were treated with oxygen plasma for 30, 60, 90, and 120 min (P30-MWCNTs, P60-MWCNTs, P90-MWCNTs, and P120-MWCNTs, resp.). Pristine MWCNTs, A-MWCNTs, and $\mathrm{P}$-MWCNTs were dispersed in 1,2-dichloroethane, then dropped onto a printed circuit board consisting of $\mathrm{Cu} / \mathrm{Au}$ electrodes used as the sensor platform. Next, EC was separately spin coated on the pristine MWCNTs, A-MWCNTs, and P-MWCNTs (EC/MWCNTs, EC/A-MWCNTs, and EC/P-MWCNTs, resp.). All sensors responded to benzene vapor at room temperature by increasing their electrical resistance which was sensitive to benzene vapor. The EC/P90-MWCNTs enabled an approximately 11-fold improvement in benzene detection compared to EC/MWCNTs. The sensitivity of all sensors would be attributed to the swelling of EC, resulting in the loosening of the MWCNT network after benzene vapor exposure. The differences of the sensing responses of the EC/MWCNTs, EC/A-MWCNTs, and EC/P-MWCNTs would be ascribed to the differences in crystallinity and functionalization of MWCNT sidewalls, suggesting that acid and oxygen plasma treatments of MWCNTs would be promising techniques for the improvement of benzene detection.
\end{abstract}

\section{Introduction}

Carbon nanotubes (CNTs) $[1,2]$ are one kind of carbon nanomaterial structure which has received widespread attention because of their exceptional properties such as high electrical $[3,4]$ and thermal conductivity [5], and large specific surface area [6]. Two and a half decades ago, CNTs were applied to the field of nanoelectronic technology for use in supercapacitors, field emitters, and gas sensors, especially in the application of CNTs as ultrasensitive gas sensors because of their high specific surface area as well as fast and high response at room temperature. Many studies 
have demonstrated ultrasensitive gas sensors based on pristine CNTs for the detection of oxidizing gases down to part-per-million levels (ppm) at room temperature [7-10]. Nevertheless, a gas sensor based on pristine CNTs is still insensitive to volatile organic compounds (VOCs) [11], especially benzene vapor. Benzene is a kind of VOC which is prevalent in outdoor air due to the emission from diesel engines. It is an abundant component in crude oil and various products derived from petrochemical processes [12]. The exposure to benzene at a level exceeding designated standards is harmful to human health and damages the environment. The National Institute for Occupational Safety and Health (NIOSH) of the U.S. limits the average concentration of benzene to lower than $0.1 \mathrm{ppm}$ for an average exposure of $10 \mathrm{~h} /$ day [13]. However, the interaction between the pristine CNTs and benzene is very weak. To enhance the sensitivity of benzene detection, the functionalization of CNTs with metal nanoparticles and polymer has been proposed as a promising approach. For example, a gas sensor based on palladium (Pd) nanoparticles (NPs) decorated on single-walled CNTs (Pd NPs/ SWCNTs) by a sputtering technique has been proposed and demonstrated for benzene detection [14]. Moreover, the Pd NP/SWCNT sensors showed weak benzene sensitivity at concentrations three orders of magnitude higher than that of the required detection threshold for ambient safety applications. In addition, multiwalled CNTs (MWCNTs) were functionalized by oxygen plasma treatment to help the adhesion and distribution of metal NPs ( $\mathrm{Rh}, \mathrm{Pd}$, or $\mathrm{Ni}$ ) on the surface of MWCNTs. Functionalized MWCNTs decorated with metal NPs could increase the sensitivity to benzene vapor. These metal NPdecorated functionalized MWCNTs can provide selective detection of benzene at trace levels with a detection limit below 50 parts per billion (ppb) [15]. Although the advantage of metal NP-decorated CNTs is the high sensitivity to benzene, the metal NP decoration technique needs a highvacuum system which is costly. Another type of gas sensor fabricated using conductive polymer-CNT composites for benzene detection at room temperature was demonstrated. The composites of SWCNTs and ethyl cellulose (EC) enhance the ability to detect benzene vapor [16]. The polymer-CNT composites were prepared in the form of CNTs dispersing in a polymer matrix based on percolation theory by a complicated polymerization process. Recently, a simple fabrication method has been proposed by coating a thin film of EC on to the acid-functionalized MWCNT network. However, the sensitivity is limited to parts per thousand level and the chemical state of the functionalized MWCNTs has not been fully explored [17].

In this work, we have proposed an approach to enhance the sensitivity of a benzene sensor using EC-coated surfacefunctionalized MWCNTs by an oxygen plasma technique. The fabricated gas sensor could detect benzene vapor in the range of parts per thousand (ppt) down to parts per million (ppm) level at room temperature. For comparison, the sensitivity improvement of MWCNTs functionalized by different methods, that is, acid treatment and oxygen plasma treatment, was investigated.

\section{Experimental Methods}

2.1. Surface Functionalization of MWCNTs by Acid or Oxygen Plasma Treatments. Chemical vapor depositiongrown commercial MWCNTs (NANOCYL ${ }^{\mathrm{TM}}$ NC7000) with a purity of $90 \%$ were used in this study. The average length and diameter of the commercial MWCNTs were $1.5 \mu \mathrm{m}$ and $9.5 \mathrm{~nm}$, respectively. Functionalization of MWCNTs by acid or oxygen plasma treatment was intentionally conducted to modify their surface reactivity. For acid treatment, $30 \mathrm{mg}$ of pristine MWCNTs were suspended in $15 \mathrm{~mL}$ of $37 \%$ hydrochloric acid $(\mathrm{HCl})$ and sonicated for $60 \mathrm{~min}$ prior to being washed with deionized water until its $\mathrm{pH}$ became neutral. Finally, the $\mathrm{HCl}$-treated MWCNTs (hereafter referred to as A60-MWCNTs) were gently dried at $100^{\circ} \mathrm{C}$ for $24 \mathrm{~h}$. For oxygen plasma treatment, $60 \mathrm{mg}$ of MWCNTs were treated with oxygen plasma for 30, 60, 90, and $120 \mathrm{~min}$ using an expanded plasma cleaner (Harrick Scientific) in order to modify their surface reactivity (hereafter referred to as P30-MWCNTs, P60-MWCNTs, P90-MWCNTs, and P120-MWCNTs, resp.).

2.2. Fabrication of Gas Sensor Device. The pristine MWCNTs, A-MWCNTs, and P-MWCNTs were separately dispersed in 1,2-dichloroethane by ultrasonication for a designated time period and subsequently dropping onto a printed circuit board consisting of interdigitated $\mathrm{Cu} / \mathrm{Au}$ electrodes with a gap of $250 \mu \mathrm{m}$. The electrical resistance of the pristine MWCNTs, A-MWCNTs, and P-MWCNTs were adjusted to approximately $1 \mathrm{k} \Omega$. EC diluted in toluene with a concentration of $1 \mathrm{wt} \%$ was continuously stirred for $24 \mathrm{~h}$. Subsequently, the EC solution was spin coated on pristine MWCNTs, A-MWCNTs, and P-MWCNTs (hereinafter called EC/MWCNTs, EC/A-MWCNTs, and EC/PMWCNTs, resp.) with a spinning speed of 3000 rounds per minute. Finally, all the sensors were heated at $100^{\circ} \mathrm{C}$ for $24 \mathrm{~h}$ to eliminate the residual toluene.

2.3. Characterization Techniques. The purity and crystallinity of pristine MWCNTs and functionalized MWCNTs were analyzed by Raman spectroscopy (Thermo Scientific ${ }^{\mathrm{TM}}$, DXR $^{\mathrm{TM}}$ SmartRaman) with an excited laser wavelength of $532 \mathrm{~nm}(2.33 \mathrm{eV})$ in the Raman shift range of 100$3500 \mathrm{~cm}^{-1}$. Pristine MWCNTs and functionalized MWCNT powder mixed with potassium bromide $(\mathrm{KBr})$ were prepared in pellet form prior to being analyzed by Fourier transforminfrared (FT-IR) spectroscopy (Perkin Elmer, Spectrum One) for identifying functional groups existing on the surface of MWCNTs. Typical FT-IR spectra in transmittance mode were scanned in a range of $400-4000 \mathrm{~cm}^{-1}$. Transmission electron microscopy (TEM, JEOL, JEM-2010) was used for observing the nanostructure of pristine MWCNTs and functionalized MWCNTs. The morphology of ECcoated functionalized MWCNTs was characterized by field emission scanning electron microscopy (FESEM, Hitachi S-4700). Finally, X-ray photoelectron spectroscopy (XPS, AXIS Ultra DLD, Kratos Analytical) was used to analyze the chemical composition and state of pristine MWCNT and functionalized MWCNT surfaces, with a base pressure 


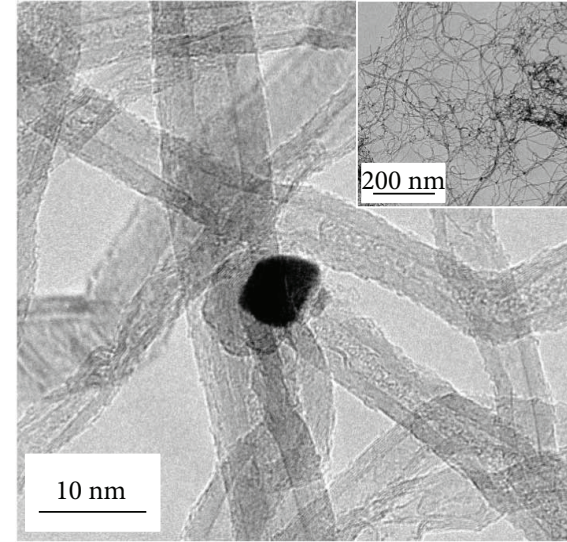

(a)

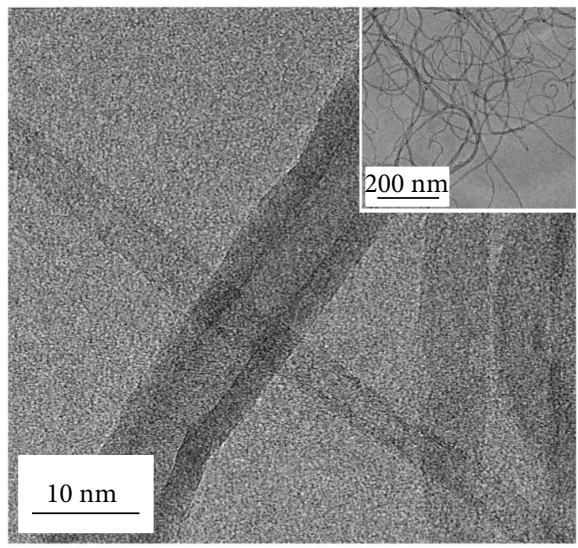

(c)

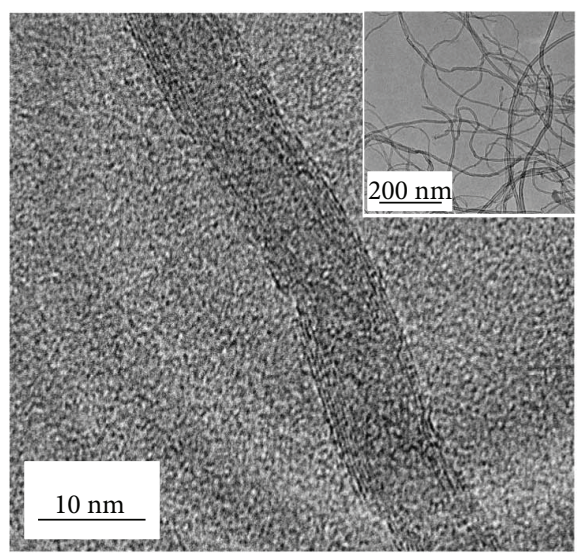

(e)

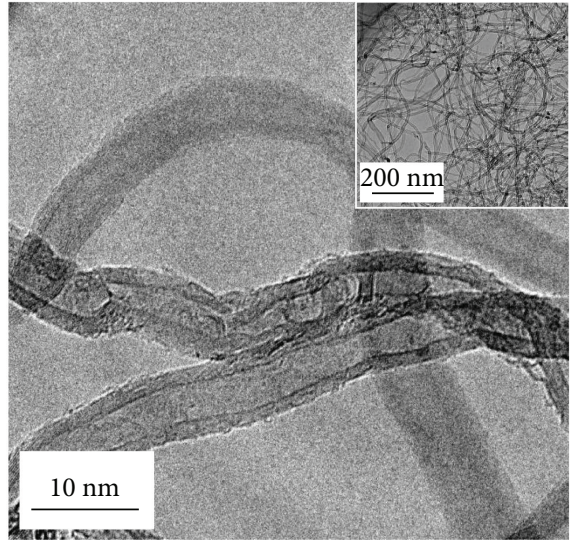

(b)

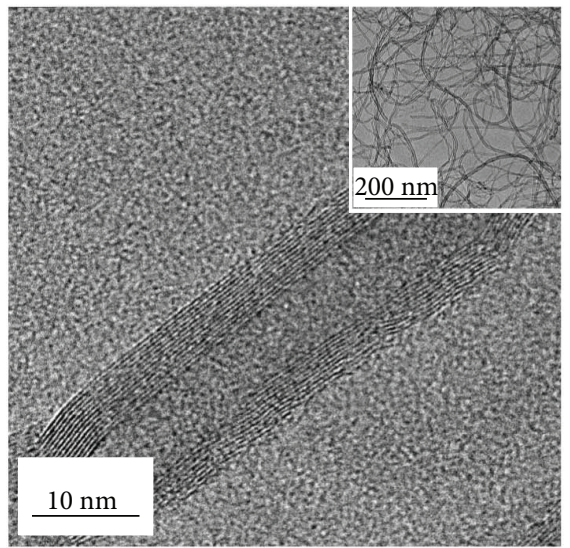

(d)

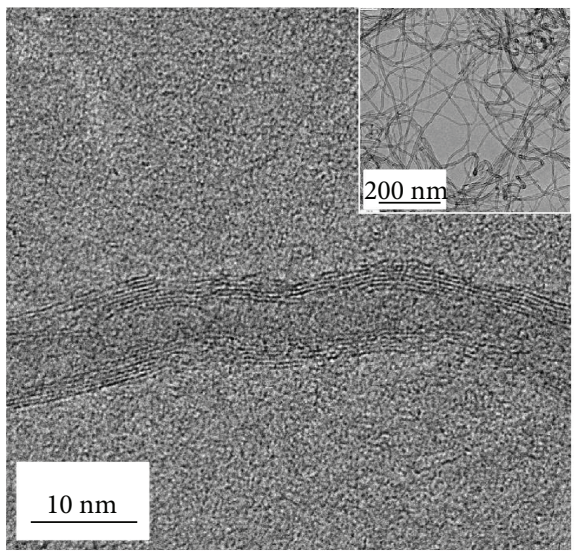

(f)

Figure 1: TEM images of (a) pristine MWCNTs, (b) A60-MWCNTs, (c) P30-MWCNTs, (d) P60-MWCNTs, (e) P90-MWCNTs, and (f) P120-MWCNTs.

of $5 \times 10^{-9}$ Torr and a monochromatic $\mathrm{Al} \mathrm{K} \alpha 1,2$ radiation of $1.4 \mathrm{kV}$.

2.4. Gas Sensor Measurement. The sensor responses of EC/ MWCNTs, EC/A-MWCNTs, and EC/P-MWCNTs to benzene vapor was experimentally examined by tracking temporary changes in electrical resistance with respect to elapsed time. Initially, each sensor was placed in a stainless chamber with $3.0 \mathrm{lpm}$ of $\mathrm{N}_{2}$ for $180 \mathrm{~s}$. Then, benzene vapor prepared from bubbling liquid benzene with $1.5 \mathrm{lpm}$ of $\mathrm{N}_{2}$ was alternatively supplied into the chamber for $180 \mathrm{~s}$. For recovery, the sensor was again purged with $3.0 \mathrm{lpm}$ of $\mathrm{N}_{2}$ until its initial electrical resistance was confirmed. The concentration of benzene vapor was varied in a range of 142-170 parts per thousand (ppt). The electrical resistance of the sensing material between the interdigitated electrodes was directly 


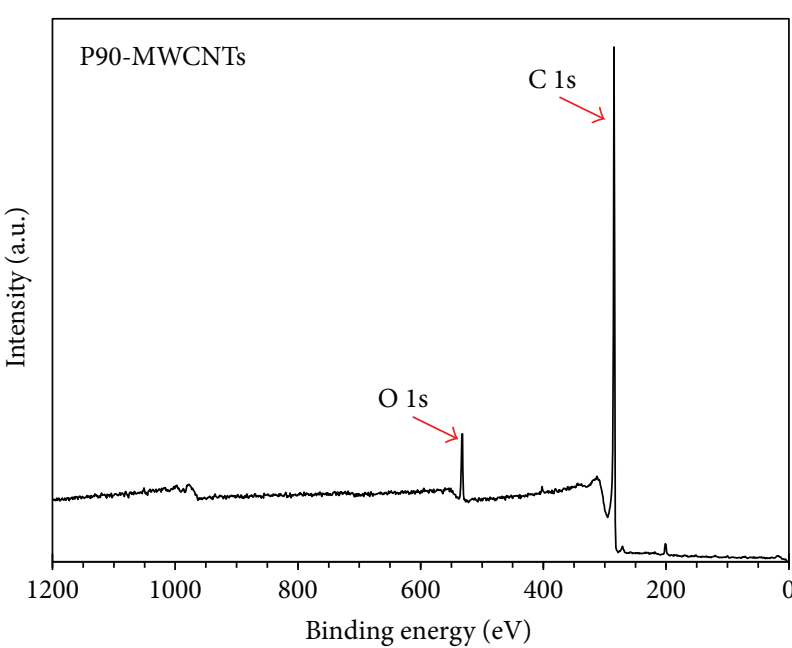

(a)

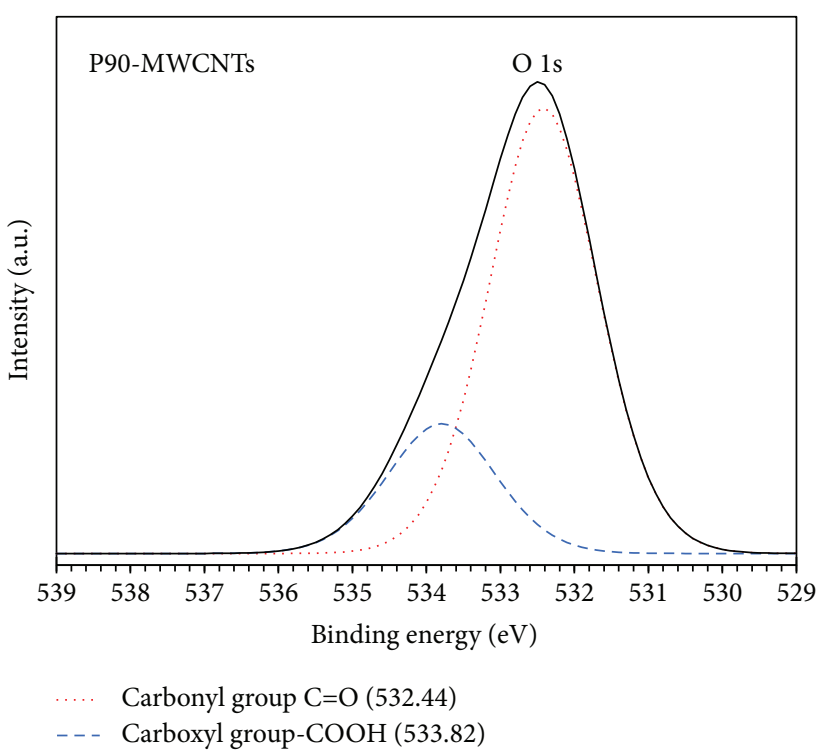

(c)

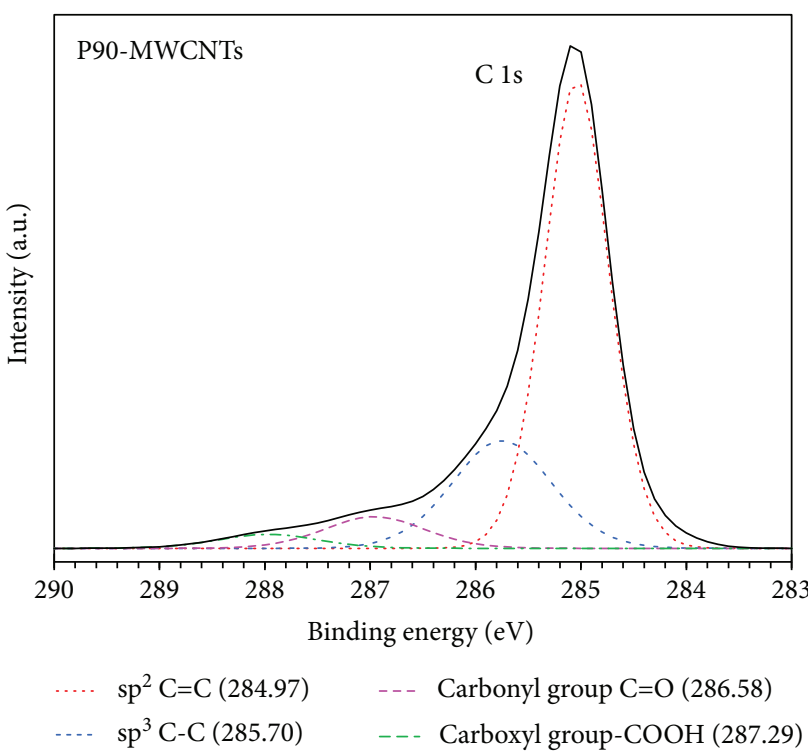

(b)

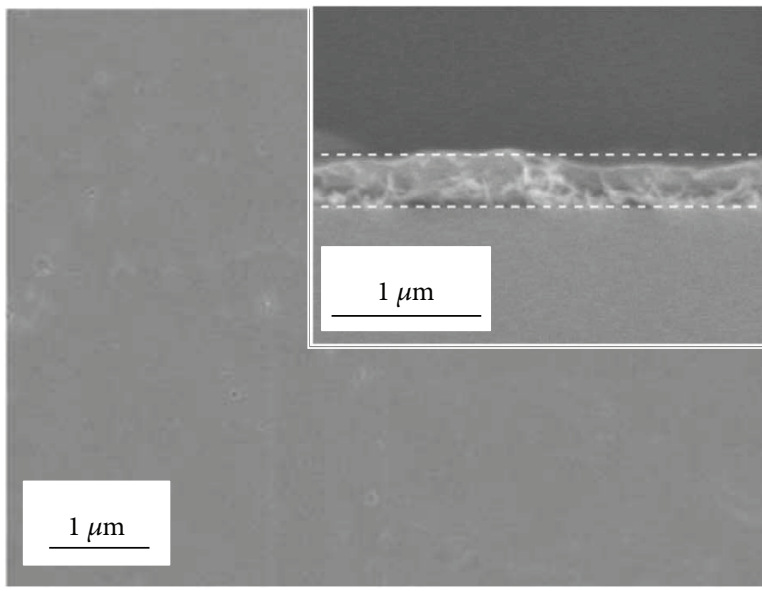

(d)

FIgure 2: (a) XPS survey and (b) C 1s and (c) O 1s spectra of the P90-MWCNTs. (d) FESEM image of EC/P90-MWCNTs (inset: crosssectional image).

measured using a Fluke NetDAQ multimeter. The sensor response (SR) could be determined using (1) whereas $R_{\text {benzene }}$ and $R_{0}$ are the resistance of a sensor exposed to benzene vapor and $\mathrm{N}_{2}$, respectively.

$$
\mathrm{SR}=\frac{R_{\text {benzene }}-R_{0}}{R_{0}}
$$

To control the concentration of benzene in the range of parts per million (ppm), the benzene liquid was dropped using a micropipette into the detection chamber by controlling the volume of benzene. The sensor was placed in the stainless steel chamber under air atmosphere for $3 \mathrm{~min}$, followed by the dropping of benzene liquid into the detection system and monitoring its resistance for $30 \mathrm{~min}$. Finally, the sensor was recovered by air exposure. The benzene concentration was in the range of $517-51,670 \mathrm{ppm}$. SR is defined using (1) whereas $R_{\text {benzene }}$ and $R_{0}$ are the electrical resistance of the sensor under benzene vapor and air atmosphere, respectively.

\section{Results and Discussion}

3.1. Nanostructure, Purity, Crystallinity, Functional Group, and Elemental Composition of Pristine MWCNTs and Functionalized MWCNTs. Figure 1 shows the TEM images of (a) pristine MWCNTs, (b) A60-MWCNTs, (c) P30MWCNTs, (d) P60-MWCNTs, (e) P90-MWCNTs, and (f) 
TABLe 1: The C 1s and O 1s components (\%) of the pristine MWCNTs, A60-MWCNTs, P60-MWCNTs, and P90-MWCNTs.

\begin{tabular}{|c|c|c|c|c|c|c|c|c|}
\hline \multirow{2}{*}{ Sample } & \multicolumn{2}{|c|}{ Element ratio (\%) } & \multicolumn{4}{|c|}{ C 1s ratio (\%) } & \multicolumn{2}{|c|}{ O 1s ratio (\%) } \\
\hline & $\mathrm{C}$ & $\mathrm{O}$ & $\mathrm{C}=\mathrm{C}$ & $\mathrm{C}-\mathrm{C}$ & $\mathrm{C}=\mathrm{O}$ & $-\mathrm{COOH}$ & $\mathrm{C}=\mathrm{O}$ & $-\mathrm{COOH}$ \\
\hline Pristine MWCNTs & 93.57 & 4.82 & 70.28 & 16.28 & 4.77 & 2.24 & 3.62 & 1.20 \\
\hline A60-MWCNTs & 96.94 & 2.65 & 68.31 & 17.03 & 7.42 & 4.18 & 1.62 & 1.03 \\
\hline P60-MWCNTs & 92.53 & 6.72 & 54.03 & 27.32 & 7.74 & 3.44 & 3.94 & 2.78 \\
\hline P90-MWCNTs & 92.30 & 6.78 & 69.72 & 15.02 & 4.80 & 2.76 & 5.25 & 1.53 \\
\hline
\end{tabular}

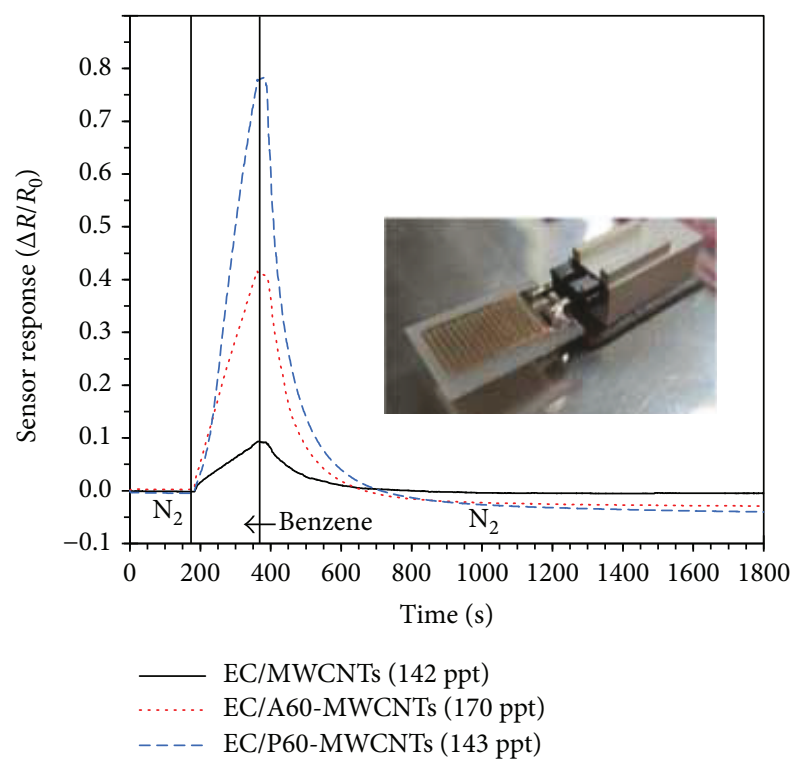

(a)

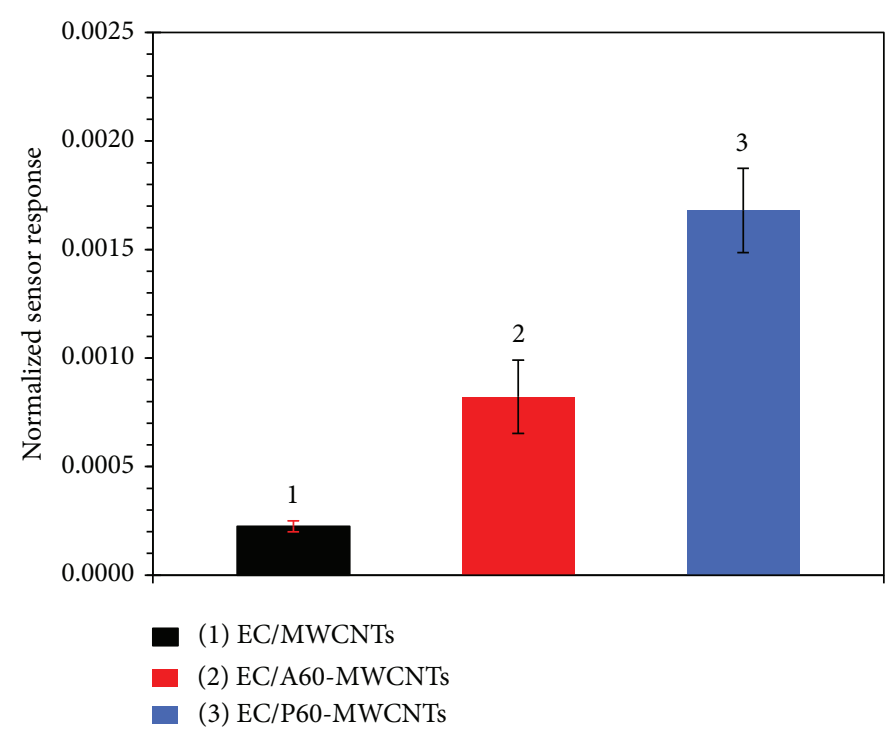

(b)

FIGURE 3: (a) Sensor response as a function of time and (b) normalized sensor response of EC/MWCNT, EC/A60-MWCNT, and EC/P60MWCNT sensors towards benzene. The inset is a photograph of the sensor device.

P120-MWCNTs. Pristine MWCNTs reveal partly amorphous carbon attached on their sidewalls and the metal catalytic nanoparticles (dark points in the inset of Figure 1(a)) which remain from the synthesis by the CVD method. After acid and oxygen plasma treatments, it was clearly found that the amorphous carbon and the metal catalytic nanoparticles (inset of Figures 1(b)-1(f)) were removed from their MWCNT sidewalls. The average diameters of pristine MWCNTs, A60-MWCNTs, P30-MWCNTs, P60-MWCNTs, P90-MWCNTs, and P120-MWCNTs were 12.0 $\pm 1.5,9.3 \pm$ $3.2,11.5 \pm 3.0,11.4 \pm 1.4,11.9 \pm 0.8$, and $11.8 \pm 1.4 \mathrm{~nm}$, respectively. There was a slight decrease in the diameters of treated MWCNTs compared to those of pristine MWCNTs, implying the detrimental damage by acid and oxygen plasma treatments. The Raman spectra of all samples consist of three characteristic peaks which are the $D^{-}, G^{-}$, and $2 D$-bands at 1340,1580 , and $2680 \mathrm{~cm}^{-1}$, respectively (data not shown). The $G$-band indicates the presence of a signal reflecting a graphitic structure that is emitted from the stretching vibration of the $\mathrm{sp}^{2}$ carbon while the $D$-band is attributed to a disordered carbon structure and the $\mathrm{sp}^{3}$ hybridized carbon. The 2D-band corresponds to second-order Raman scattering using a two-phonon process [18]. The intensity ratio of the $G$ and $D$ bands $\left(I_{G} / I_{D}\right)$ is a representation of the crystallinity of MWCNTs and treated MWCNTs. The $I_{G} / I_{D}$ of pristine MWCNTs, A60-MWCNTs, P30MWCNTs, P60-MWCNTs, P90-MWCNTs, and P120MWCNTs were $0.72 \pm 0.03,0.76 \pm 0.02,0.73 \pm 0.03,0.97$ $\pm 0.03,0.84 \pm 0.09$, and $0.74 \pm 0.05$, respectively. The higher $I_{G} / I_{D}$ of the A60-MWCNTs, P30-MWCNTs, and P60-MWCNTs compared with those of the pristine MWCNTs would suggest that the crystallinity of the treated MWCNTs was improved due to the removal of disordered carbon structures and impurities. However, with a longer time of oxygen plasma treatment up to $90 \mathrm{~min}$, the oxygen radical generated from oxygen plasma may etch the sidewall of MWCNTs, resulting in the formation of a defect and the decrease in the $I_{G} / I_{D}$ ratio.

The change in surface functional groups of pristine MWCNTs after acid and oxygen plasma treatments was analyzed by FT-IR (data not shown). The peak at $3780 \mathrm{~cm}^{-1}$ is O-H stretching vibration [19]. All samples showed a broad transmission band at around $3430 \mathrm{~cm}^{-1}$ corresponding to the $\mathrm{O}-\mathrm{H}$ stretching vibration which could be due to absorbed water, O-H, or carboxylic groups on MWCNT surfaces [20]. The peaks at 2920 and $2850 \mathrm{~cm}^{-1}$ could contribute to $\mathrm{sp}^{3}$ (C-H) vibration, originating from the surface or sidewalls of CNTs [21]. The small band at around 1560 and 


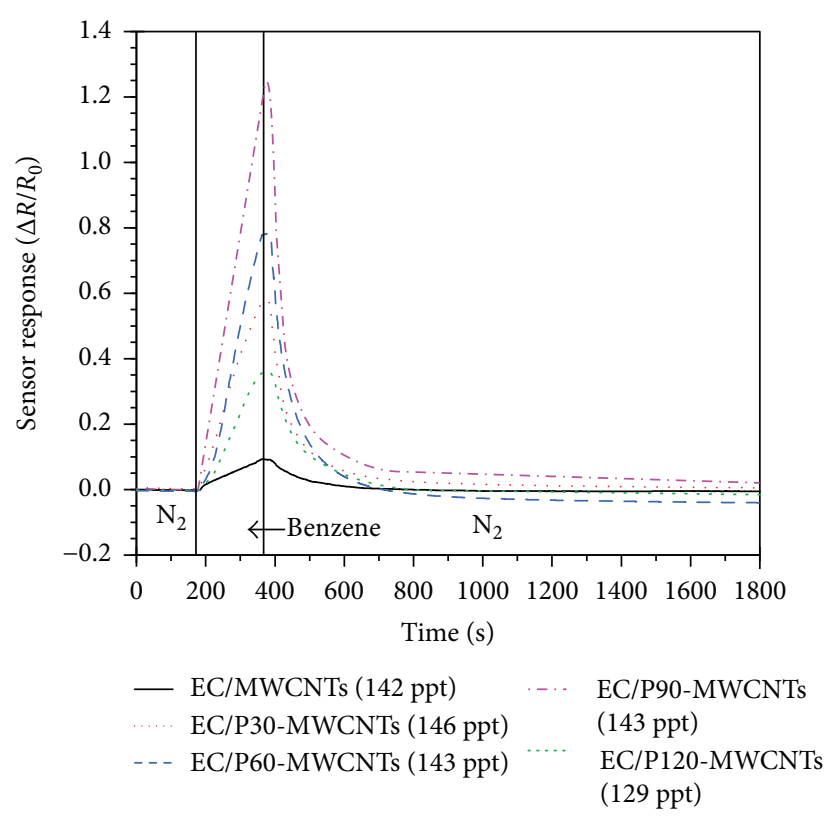

(a)

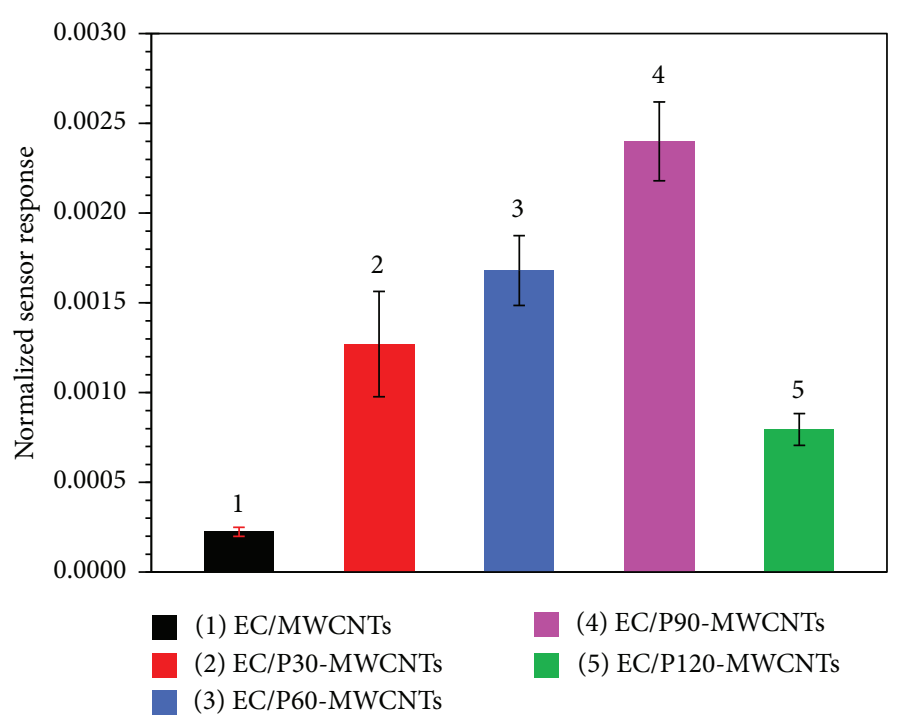

(b)

Figure 4: (a) Sensor response as a function of time and (b) normalized sensor response of EC/MWCNTs, EC/P30-MWCNTs, EC/P60MWCNTs, EC/P90-MWCNTs, and EC/P120-MWCNTs toward benzene.

$1020 \mathrm{~cm}^{-1}$ could be attributed to the presence of $(\mathrm{C}=\mathrm{C})$ and (C-O) stretching $[22,23]$. Furthermore, the new peak appeared at a wave number of $1380 \mathrm{~cm}^{-1}$ from AMWCNTs and P-MWCNTs. The peak at $1380 \mathrm{~cm}^{-1}$ is due to $(\mathrm{C}-\mathrm{O})$ stretching and $(\mathrm{O}-\mathrm{H})$ bending deformation in $(-\mathrm{COOH})$ [24]. These results indicate that oxygen-plasma treatments are an effective method to functionalize oxygenated functional groups of $(-\mathrm{OH})$ and $(-\mathrm{COOH})$ on the walls of MWCNTs.

XPS was used to measure the chemical composition and chemical state of pristine MWCNTs, A-MWCNTs, and P-MWCNTs. Figure 2(a) shows the XPS survey spectrum of P90-MWCNTs. The spectrum consists of C $1 \mathrm{~s}$ and $\mathrm{O} 1 \mathrm{~s}$ peaks at 285 and $533 \mathrm{eV}$, respectively. For the $\mathrm{C} 1 \mathrm{~s}$ peak, there are four different carbon groups in the XPS spectrum: $\mathrm{sp}^{2} \mathrm{C}=\mathrm{C}$ at $285.0 \mathrm{eV}, \mathrm{sp}^{3} \mathrm{C}-\mathrm{C}$ at $285.7 \mathrm{eV}$, the carbonyl group $\mathrm{C}=\mathrm{O}$ at $286.6 \mathrm{eV}$, and the carboxyl group $-\mathrm{COOH}$ at $287.3 \mathrm{eV}$ as shown in Figure 2(b) [25]. In the case of the $\mathrm{O} 1 \mathrm{~s}$ peak, there are two different oxygen groups in the XPS spectrum: $\mathrm{C}=\mathrm{O}$ at $532.4 \mathrm{eV}$ and $\mathrm{C}-\mathrm{O}$ at $533.8 \mathrm{eV}$ as shown in Figure 2(c) [26]. The components (\%) of $\mathrm{C} 1 \mathrm{~s}$ and $\mathrm{O} 1 \mathrm{~s}$ of pristine MWCNTs, A-MWCNTs, and $\mathrm{P}$-MWCNTs are summarized in Table 1 . The relative percentages of carbon in P60-MWCNTs and P90-MWCNTs decrease from $93.57 \%$ to 92.53 and $92.30 \%$, respectively, while the percentages of oxygen increase from $4.82 \%$ to $6.72 \%$ and $6.78 \%$, respectively. The results showed that oxygen plasma treatment significantly generated oxygen species on MWCNTs [25, 27]. Figure 2(d) shows the top and cross-sectional (inset) views of FESEM images of EC/P90MWCNTs. The P90-MWCNT network was shown to be buried in the EC matrix. The thickness of the EC coating on the P90-MWCNTs was $0.22 \mu \mathrm{m}$.
3.2. Sensing Characteristics of EC/MWCNT, EC/A-MWCNT, and EC/P-MWCNT Sensors. The sensor responses of EC/ MWCNTs, EC/A60-MWCNTs, and EC/P60-MWCNTs under benzene vapor are shown in Figure 3(a). The inset of Figure 3(a) shows a photograph of the sensor device. All sensors exhibited an increase in the electrical resistance after exposure to benzene vapor and completely recovered to the initial values after being purged with $\mathrm{N}_{2}$ gas. Figure 3(b) shows the normalized sensor response of the EC/MWCNT, EC/A60-MWCNT, and EC/P60-MWCNT sensors. It could be observed that the normalized sensor response of EC/ A60-MWCNTs and EC/P60-MWCNTs were 3.66- and 7.47-fold higher than that of EC/MWCNTs, respectively. The preliminary sensor response results indicated that the acid- and oxygen plasma-treated MWCNTs improved the sensor response to benzene vapor. Next, the responses of the EC-coated sensors on different times of oxygen plasma treatment of MWCNTs to benzene vapor were investigated. Figure 4(a) shows the sensor response of EC/MWCNTs, EC/P30-MWCNTs, EC/P60-MWCNTs, EC/P90-MWCNTs, and EC/P120-MWCNTs exposed to benzene vapor. The electrical resistance of all sensors increased upon benzene exposure and decreased after replacing benzene with $\mathrm{N}_{2}$ gas. Figure 4(b) shows the normalized sensor response of EC/MWCNTs, EC/P30-MWCNTs, EC/P60-MWCNTs, EC/ P90-MWCNTs, and EC/P120-MWCNTs to benzene vapor. The normalized sensor response is in the following order: EC/MWCNTs $<$ EC/P30-MWCNTs $<$ EC/P120-MWCNTs $<$ EC/P60-MWCNTs $<$ EC/P90-MWCNTs. The normalized sensor response of EC/P90-MWCNTs was 10.68-fold higher than that of EC/MWCNT. The sensing mechanism of EC/ MWCNTs, EC/A-MWCNTs, and EC/P-MWCNTs could be attributed to the swelling of EC [16, 28-32]. Moreover, 


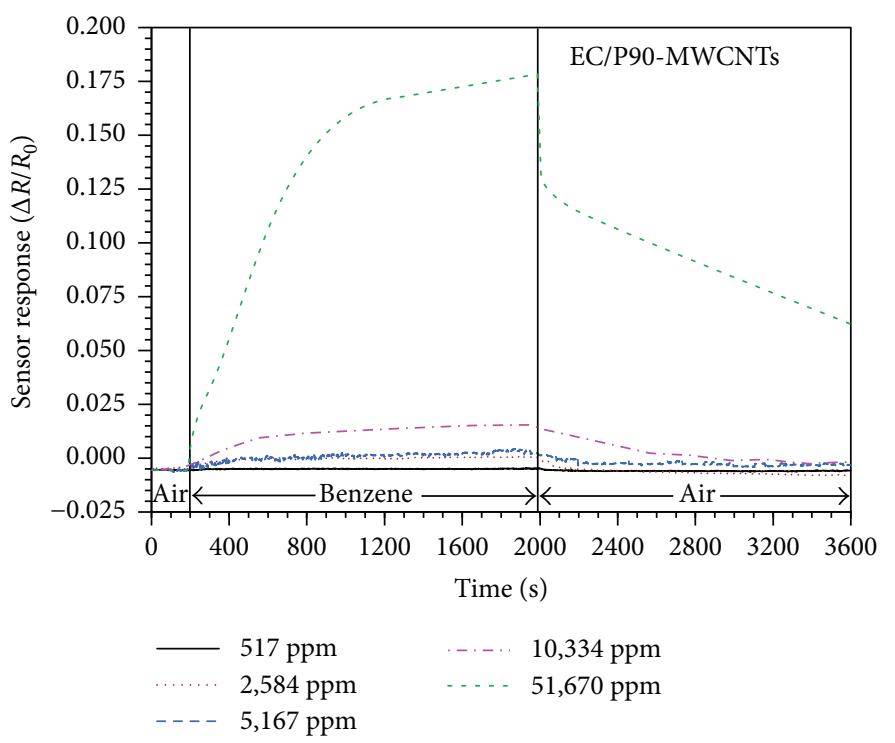

(a)

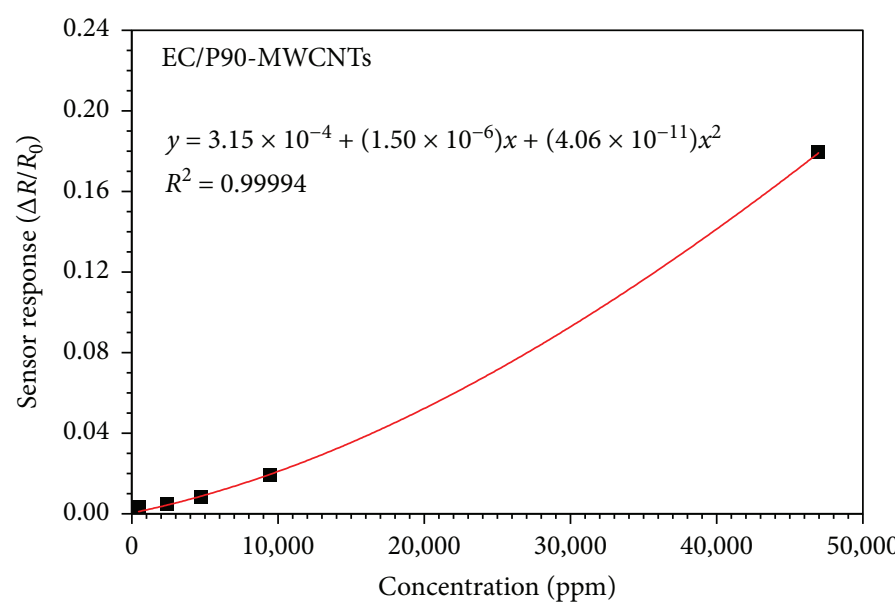

- Experimental Fitting

(b)

FIGURE 5: (a) Sensor response of EC/P90-MWCNTs to benzene and (b) relationship between sensor response and benzene concentration.

the increase of sensor response could be explained by the oxygenated functional groups after oxygen plasma treatments. The oxygenated functional groups increased the interaction between oxygen plasma-treated MWCNTs and EC. Upon benzene exposure, EC started to swell, resulting in the loosening of the MWCNT network and followed by a large increase in the electrical resistance of MWCNTs [33, 34]. These results implied that the oxygenated functional groups forming on the surface of MWCNTs by acid and oxygen plasma treatments play an important role in benzene detection. The relative amount of oxygen in MWCNTs seemingly increased with the increase of the oxygen plasma treatment time. Nevertheless, the sensor response of EC/P120-MWCNTs is lower than that of EC/P60-MWCNTs and EC/P90-MWCNTs. These results could be explained by the increasing of oxygen plasma treatment time. The higher oxygen plasma treatment time makes the MWCNT surface to be etched and destroyed, which is consistent with TEM results (Figure 1(f)). Thus, the interaction between P120-MWCNTs and EC is lower compared to P60-MWCNTs and P90-MWCNTs, resulting in a lower sensor response.

The sensor response of the EC/P90-MWCNTs under benzene vapor in the concentration range of 517-51,670 ppm was shown in Figure 5(a). The EC/P90-MWCNTs could detect benzene vapor down to ppm level. The electrical resistance of EC/P90-MWCNTs increased under benzene exposure and recovered to their initial resistance under air exposure. The higher the benzene concentration, the higher is the sensor response. When the benzene concentration increases, a higher quantity of benzene molecules adsorb on EC/P90-MWCNTs, thus accelerating the EC swelling level, resulting in an increase in electrical resistance change and a decrease in response time. For benzene detection at $517 \mathrm{ppm}$, the gas sensor 
barely responded to benzene vapor. It would be the limitation of the fabricated gas sensor. For benzene detection at a 51,670 ppm concentration, the gas sensor was unable to recover to its initial resistance within $30 \mathrm{~min}$. This may be due to a large swelling level at high concentration that takes a longer recovery time than that of a low swelling level at low concentration. Figure 5(b) represents the relationship between the sensor response of EC/P90-MWCNTs and benzene concentration. The results show the relation between sensor response and benzene concentrations as a curved graph. This result clearly indicates that the combination of oxygen plasma treatment and EC functionalization of CNTs is a promising approach to improve benzene sensor sensitivity down to ppm-level detection.

\section{Conclusion}

The gas sensors based on EC-coated surface-functionalized MWCNTs have been successfully demonstrated to detect benzene vapor from ppt down to ppm level at room temperature. Oxygen plasma and acid treatment techniques were employed for MWCNT functionalization. The fabricated sensor from EC/P90-MWCNTs exhibited a 10.68fold improvement in the response to benzene detection compared to the EC/MWCNTs. The improvement of sensor response to benzene vapor would be ascribed to the binding interaction between functional groups on the surface of MWCNTs and coated EC on MWCNTs. The higher binding interaction improves the adhesion of EC on the functionalized MWCNT surface, resulting in the higher response of EC-coated functionalized MWCNTs compared to that of EC-coated pristine MWCNTs. These results suggest that the integration of acid- or oxygen plasma-treated MWCNTs and EC would be promising approaches for the improvement of the benzene-detecting sensor.

\section{Conflicts of Interest}

The authors declare that there is no conflict of interests regarding the publication of this paper.

\section{Authors' Contributions}

Thanattha Chobsilp and Worawut Muangrat contributed equally to this work.

\section{Acknowledgments}

The authors acknowledge the financial and facility support from the PTT Public Company Limited via the collaborative project granted to CEPT, CU. This work is also partly supported by the National Nanotechnology Center (NANOTEC), NSTDA, Ministry of Science and Technology, Thailand, through its program of Center of Excellence Network.

\section{References}

[1] S. Iijima and T. Ichihashi, "Single-shell carbon nanotubes of 1nm diameter," Nature, vol. 363, no. 6430, pp. 603-605, 1993.
[2] S. Iijima, "Helical microtubules of graphitic carbon," Nature, vol. 354 , no. 6348 , pp. 56-58, 1991.

[3] T. W. Odom, "Current chemistry: electronic properties of single-walled carbon nanotubes," Australian Journal of Chemistry, vol. 54, no. 10, pp. 601-604, 2001.

[4] S. Hong and S. Myung, "Nanotube electronics: a flexible approach to mobility," Nature Nanotechnology, vol. 2, no. 4, pp. 207-208, 2007.

[5] E. Pop, D. Mann, Q. Wang, K. Goodson, and H. Dai, "Thermal conductance of an individual single-wall carbon nanotube above room temperature," Nano Letters, vol. 6, no. 1, pp. 96100, 2006.

[6] A. Peigney, C. Laurent, E. Flahaut, R. R. Bacsa, and A. Rousset, "Specific surface area of carbon nanotubes and bundles of carbon nanotubes," Carbon, vol. 39, no. 4, pp. 507-514, 2001.

[7] J. Kong, N. R. Franklin, C. Zhou et al., "Nanotube molecular wires as chemical sensors," Science, vol. 287, no. 5453, pp. 622-625, 2000.

[8] C. Cantalini, L. Valentini, I. Armentano, L. Lozzi, J. M. Kenny, and S. Santucci, "Sensitivity to $\mathrm{NO}_{2}$ and cross-sensitivity analysis to $\mathrm{NH}_{3}$, ethanol and humidity of carbon nanotubes thin film prepared by PECVD," Sensors and Actuators B: Chemical, vol. 95, no. 1-3, pp. 195-202, 2003.

[9] J. Li, Y. Lu, Q. L. Ye, J. Han, and M. Meyyappan, "Carbon nanotube sensors for gas and organic vapor detection," Nano Letters, vol. 3, no. 7, pp. 929-933, 2003.

[10] W. Wongwiriyapan, S. I. Honda, H. Konishi et al., "Singlewalled carbon nanotube thin-film sensor for ultrasensitive gas detection," Japanese Journal of Applied Physics, vol. 44, no. 16, pp. L482-L484, 2005.

[11] J. N. Armor, "Environmental catalysis," Applied Catalysis B: Environmental, vol. 1, no. 4, pp. 221-256, 1992.

[12] C. Farrow, H. Wheeler, N. Bates, and V. Murray, The Chemical Incidient Management Handbook, The stationery office, London, 2000.

[13] "The National Institute for Occuapational Safety and Health," 2017, April 2016, https://www.cdc.gov/niosh/npg/npgd0049 .html.

[14] Y. Lu, C. Partridge, M. Meyyappan, and J. Li, “A carbon nanotube sensor array for sensitive gas discrimination using principal component analysis," Journal of Electroanalytical Chemistry, vol. 593, no. 1-2, pp. 105-110, 2006.

[15] R. Leghrib, A. Felten, F. Demoisson, F. Reniers, J. J. Pireaux, and E. Llobet, "Room-temperature, selective detection of benzene at trace levels using plasma-treated metal-decorated multiwalled carbon nanotubes," Carbon, vol. 48, no. 12, pp. 3477-3484, 2010.

[16] S. M. Cho, Y. J. Kim, Y. S. Kim, Y. Yang, and S. Ha, "The application of carbon nanotube-polymer composite as gas sensing materials," in SENSORS, 2004 IEEE, pp. 701-704, Vienna, Austria, October 2004.

[17] T. Chobsilp, W. Wongwiriyapan, C. Issro et al., "Study on effect of acid and heat treatments of multi-walled carbon nanotubes on benzene detection," Advances in Materials Research, vol. 1103, pp. 105-111, 2015.

[18] C. Thomsen and S. Reich, "Double resonant Raman scattering in graphite," Physical Review Letters, vol. 85, no. 24, pp. 5214$5217,2000$.

[19] R. Vijayalakshmi, M. Jayachandran, and C. Sanjeeviraja, "Structural, electrochromic and FT-IR studies on electrodeposited 
tungsten trioxide films," Current Applied Physics, vol. 3, no. 2-3, pp. 171-175, 2003.

[20] M. Khazaee, W. Xia, G. Lackner et al., "Dispersibility of vapor phase oxygen and nitrogen functionalized multi-walled carbon nanotubes in various organic solvents," Scientific Reports, vol. 6, article 26208, 2016.

[21] C. Zhao, L. Ji, H. Liu et al., "Functionalized carbon nanotubes containing isocyanate groups," Journal of Solid State Chemistry, vol. 177, no. 12, pp. 4394-4398, 2004.

[22] F. A. Abuilaiwi, T. Laoui, M. Al-harthi, and M. A. Atieh, "Modification and functionalization of multiwalled carbon nanotube (MWCNT) via Fischer esterification," The Arabian Journal for Science and Engineering, vol. 35, no. 1C, pp. 3748, 2010.

[23] M. Busquets-Fité, E. Fernandez, G. Janer et al., "Exploring release and recovery of nanomaterials from commercial polymeric nanocomposites," Journal of Physics: Conference Series, vol. 429, article 12048, 2013.

[24] D. S. Bag, R. Dubey, N. Zhang et al., "Chemical functionalization of carbon nanotubes with 3-methacryloxypropyltrimethoxysilane (3-MPTS)," Smart Materials and Structures, vol. 13, no. 5, pp. 1263-1267, 2004.

[25] R. Ionescu, E. H. Espinosa, E. Sotter et al., "Oxygen functionalisation of MWNT and their use as gas sensitive thick-film layers," Sensors and Actuators B: Chemical, vol. 113, no. 1, pp. 36-46, 2006.

[26] A. O. Lobo, S. C. Ramos, E. F. Antunes, F. R. Marciano, V. J. Trava-Airoldi, and E. J. Corat, "Fast functionalization of vertically aligned multiwalled carbon nanotubes using oxygen plasma," Materials Letters, vol. 70, pp. 89-93, 2012.

[27] K. P. Yoo, K. H. Kwon, N. K. Min, M. J. Lee, and C. J. Lee, "Effects of $\mathrm{O}_{2}$ plasma treatment on $\mathrm{NH}_{3}$ sensing characteristics of multiwall carbon nanotube/polyaniline composite films," Sensors and Actuators B: Chemical, vol. 143, no. 1, pp. 333340, 2009.

[28] W. Muangrat, T. Chodjarusawad, R. Maolanon, S. Pratontep, S. Porntheeraphat, and W. Wongwiriyapan, "Poly(methyl methacrylate) and thiophene-coated single-walled carbon nanotubes for volatile organic compound discrimination," Japanese Journal of Applied Physics, vol. 55, no. 2S, article 02BD04, 2016.

[29] W. Muangrat, V. Yordsri, R. Maolanon, S. Pratontep, S. Porntheeraphat, and W. Wongwiriyapan, "Hybrid gas sensor based on platinum nanoparticles/poly(methyl methacrylate)-coated single-walled carbon nanotubes for dichloromethane detection with a high response magnitude," Diamond and Related Materials, vol. 65, pp. 183-190, 2016.

[30] S. Nag, A. Sachan, M. Castro, V. Choudhary, and J. F. Feller, "Spray layer-by-layer assembly of POSS functionalized CNT quantum chemo-resistive sensors with tuneable selectivity and ppm resolution to VOC biomarkers," Sensors and Actuators B: Chemical, vol. 222, pp. 362-373, 2016.

[31] J. F. Fennell, H. Hamaguchi, B. Yoon, and T. M. Swager, "Chemiresistor devices for chemical warfare agent detection based on polymer wrapped single-walled carbon nanotubes," Sensors, vol. 17, no. 5, p. 982, 2017.

[32] J. C. Chiou and C. C. Wur, "A wearable and wireless gassensing system using flexible polymer/multi-walled carbon nanotube composite films," Polymers, vol. 9, no. 12, p. 457, 2017.
[33] A. A. Koós, Z. E. Horváth, Z. Osváth et al., "STM investigation of carbon nanotubes connected by functional groups," Materials Science and Engineering: C, vol. 23, no. 6-8, pp. 10071011, 2003.

[34] A. Garg and S. B. Sinnott, "Effect of chemical functionalization on the mechanical properties of carbon nanotubes," Chemical Physics Letters, vol. 295, no. 4, pp. 273-278, 1998. 


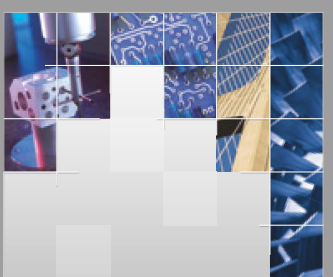

\section{Enfincering}
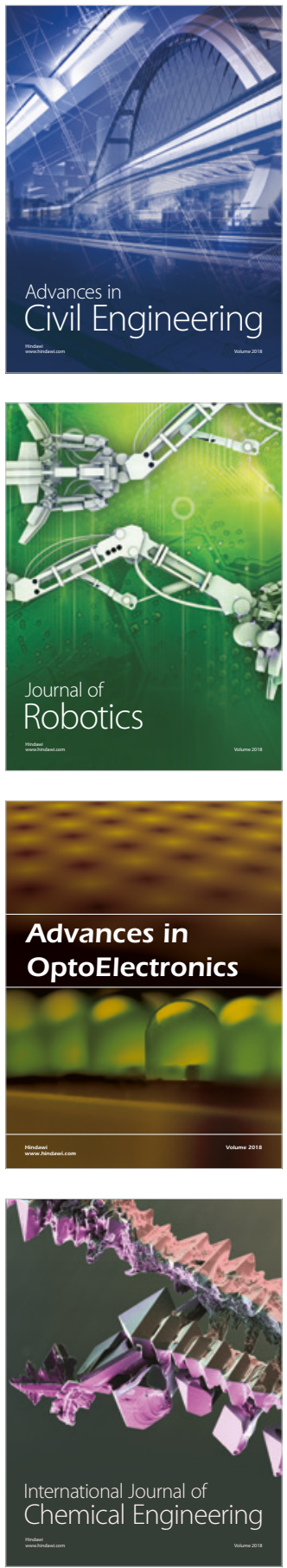

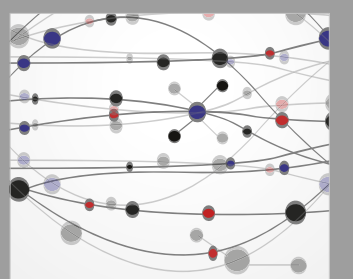

\section{Rotating \\ Machinery}

The Scientific World Journal

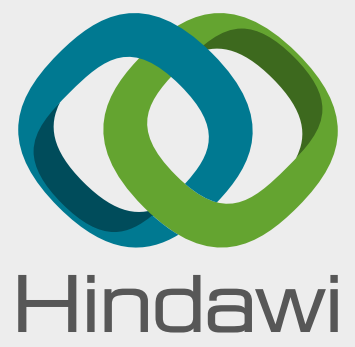

Submit your manuscripts at

www.hindawi.com
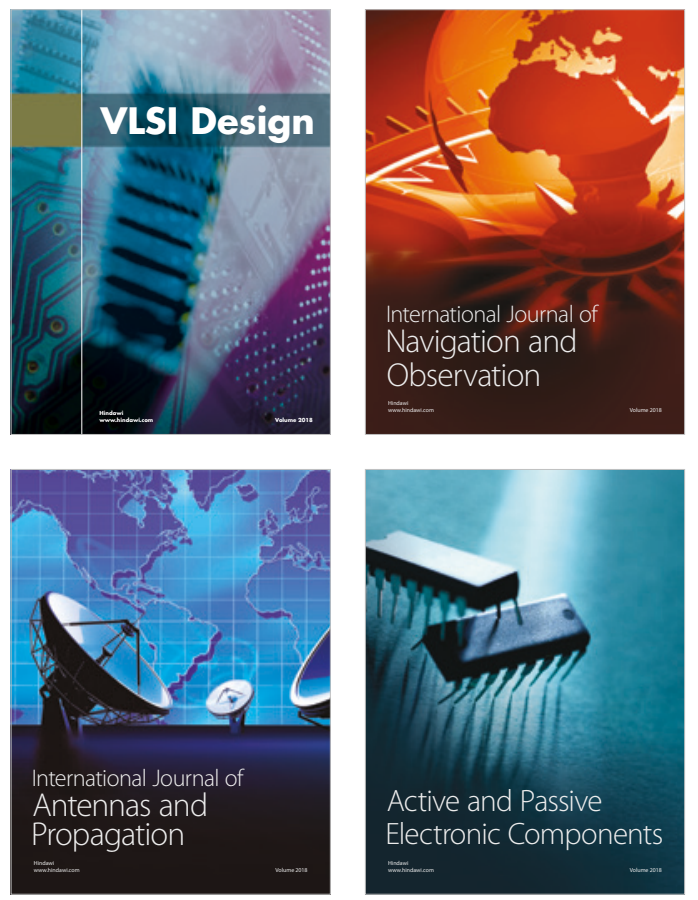
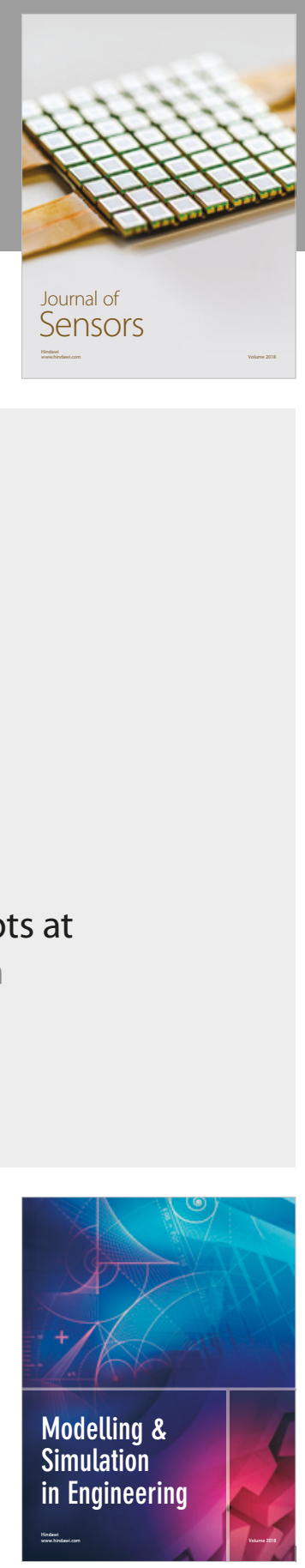

\section{Advances \\ Multimedia}
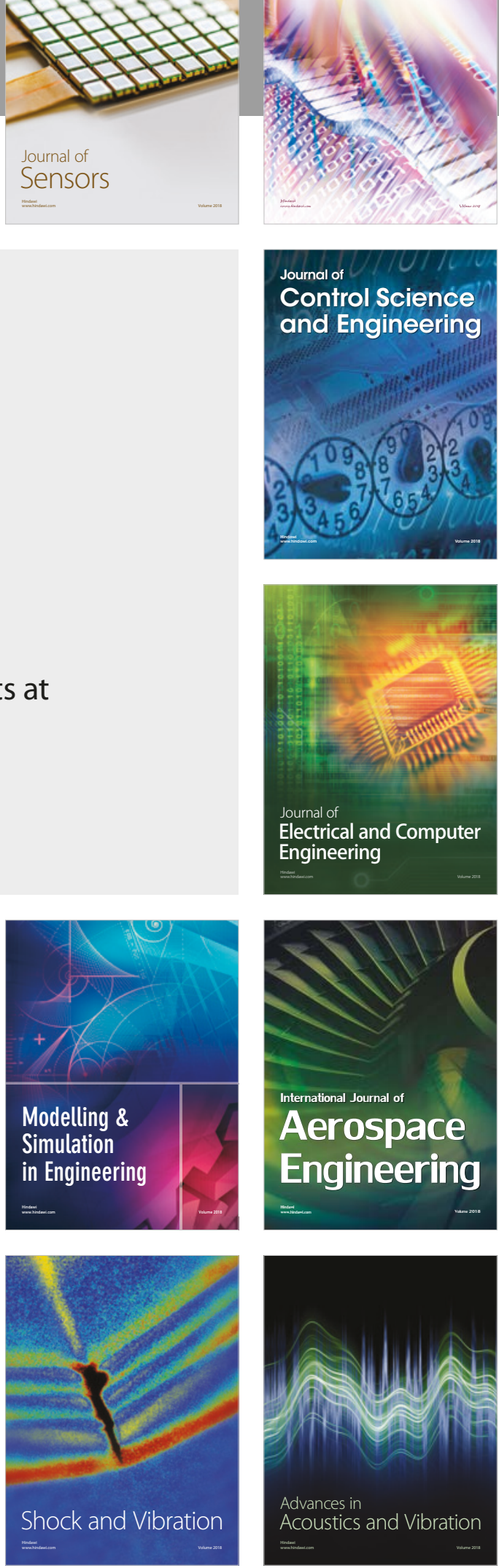